\title{
Effect of Sports Industry Structure on Sports Consumption: An Empirical Study Based on Survey Data of Suzhou
}

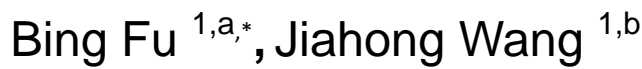 \\ ${ }^{1}$ Physical Education Institute of Jiangsu Soochow University, Suzhou, Jiangsu, China \\ a254541127@qq.com, bjhwang@suda.edu.cn \\ ${ }^{*}$ Corresponding author
}

Keywords: Sports industry, sports consumption, an empirical study.

Abstract. In order to put forward the pointed countermeasure proposal to guide the sports consumption and optimize the sports industrial structure, this article adopt the methods of investigation, literature study and empirical study, use the Soochow to be a sample study and then use Eviews and Stata to be the analysis software to do an empirical study on the effect of different indicators of sport industry structure to sports consumption. The results show that: 1)The sports consumption has a long-term positive response to the sports industry disturbance. 2)The sports industrial structure have a significant correlation with the sports consumption, from the greatest to the least, is the manufacturing of sports and sports related products, the stadium construction activities, other sports activities and sports intermediary activities. 3)The other indicators show no significant correlation with sports consumption, and sports organization and management activities even plays a role in no significant negative correlation, this is where sports industrial structure needs to be improved. 4)The development of sports consumption must depend on the level of regional economic development and the industrial environment it belongs to.$$
\text { 付冰 }{ }^{1, a}{ }^{*} \text {, 王家宏 }{ }^{1, b}
$$ \\ 1苏州大学体育学院, 苏州, 江苏, 中国 \\ a254541127@qq.com, b jhwang@suda.edu.cn \\ *通讯作者}

体育产业结构对体育消费的影响: 基于苏州市调查数据的实证研究

关键词：体育产业; 体育消费; 实证

中文摘要. 采用调查法、文献研究法和实证分析法, 以苏州市调查数据为例, 利用Eviews数 量经济学软件和Stata统计分析软件实证考察体育产业结构不同指标对体育消费的影响程度, 以期为引导体育消费、优化产业结构提出针对性的意见和建议。结果表明：1）体育消费对体 育产业的扰动产生了长期正向的响应。2）对体育消费产生正向影响的体育产业指标，按显著 影响力大小依次为体育用品及相关体育产品的制造、体育场馆建筑活动、包括体育培训、体 育传媒服务等在内的其他体育活动以及体育中介活动。3）体育产业的其他指标与体育消费没 有表现出明显的相关性, 体育组织管理活动甚至起到了不显著的负相关作用, 这是体育产业 结构发展亟待完善之处。4)体育消费的发展离不开地区经济的发展水平以及所属的产业环境。

\section{1. 引言}

90 年代以来, 我国市场供需形势发生了本质性转变, 遏制经济增长的因素由供给侧转变 为需求侧, 自此, 扩大我国消费需求便成为社会经济发展进程中一项常态化、长期化的课题。 在此过程中, 我国体育产业渐露锋芒, 体育消费市场也越来越受到政产学研界的广泛重视。 
日前, 为促进居民消费扩大和升级, 带动产业结构调整升级, 加快培育发展新动力, 国家发 改委发布了《关于印发促进消费带动转型升级行动方案的通知》, 其中体育消费成为重要内 容之一。 ${ }^{[1]} 2016$ 年 5 月, 国家体育总局发布《体育发展 “十三五” 规划》，对 “调整体育产 业结构”、“促进体育消费” 和 “引导体育消费” 提出了新任务和新要求。 ${ }^{[2]}$ 基于此, 研究 影响体育产业结构与体育消费的关系问题就显得尤其迫切。

随着体育市场的急剧扩张和政策红利不断落地，我国体育产业进入发展的黄金时期，体 育消费呈现出广阔的发展空间，体育消费与体育产业显示出明显的互动性 ${ }^{[3]}$ ，一方面，体育 产业所释放的市场活力能对体育消费起到促进和环境保障的作用; 另一方面, 体育消费作为 体育经济的重要组成部分, 是衡量人们对体育产业认同性、需求性的直接体现。关于两者关 系的研究, 于振峰、王庆伟 (1998) 认为体育消费是体育产业的前提和基础, 体育产业又是 消费的重要推动力 ${ }^{[4]}$; 朱汉义（2006）认为消费结构能够促进产业结构优化，体育产业的发 展能够拉动体育消费 ${ }^{[5]}$; 李国茂（2015）认为，体育产业结构发展失衡是影响体育消费的因 素之一[6]。

可以看出，体育产业结构对体育消费存在一定的影响关系，但对于两者的关系研究多集 中于理论分析层面, 缺乏直观的实证研究, 而体育产业构成包含多个指标, 不同指标对体育 消费的影响也不尽相同。因此, 本研究采用理论分析与实证研究相结合的方式, 以苏州市为 研究样本, 2008 年至 2014 年为研究区间, 在对体育消费结构及发展进行分析的基础上, 实 证考察体育产业结构不同指标对体育消费的影响程度, 以期为引导体育消费、优化产业结构 促进体育消费提出意见和建议。

\section{2．苏州市体育消费结构现状分析}

苏州市体育产业发展迅速，同时体育消费也不断显现出其充满朝气的发展空间，受 2008 年北京奥运会的联动效应, 体育消费总额增加明显, 2009 年有所下降, 但之后至今呈现出平 稳增长的趋势, 且与体育产业增加值发展趋势一致, 但增率低于体育产业增加值增率, 具体 如表 1 所示。

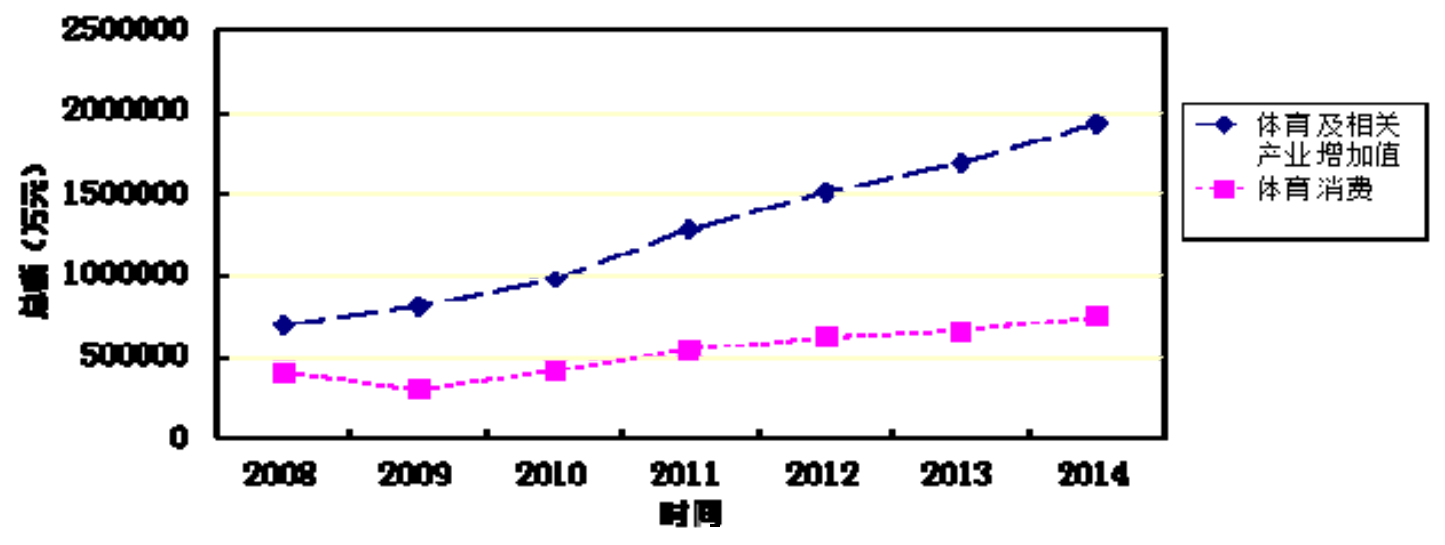

图1 体育及相关产业增加值及体育消费变动趋势

苏州市体育消费支出指标主要包括 3 部分，消费体育用品(含运动服饰) 、体育健身休闲 消费以及体育彩票, 由于 2008 年体育消费分类别数据有缺失, 因此体育消费及各类别变化趋 势从 2009 年开始分析 (如图 2)，可以看出，体育彩票人均消费支出浮动较大，但依旧占据 半壁江山, 2011 年趋势线斜率最高, 占比最大, 之后略微下降然后回升; 其次是体育用品消 费支出, 2011 年趋势线斜率最低, 占比最低, 之后趋于稳定; 占比最低为体育健身休闲消费 支出, 而且波动最大, 2008 年北京奥运会期间占比达到最大后开始下降, 至 2012 年开始回 升, 并平稳增长。

为了对公众的体育消费倾向及变化进行更直观地分析，本研究又对体育消费及分类别的 边际消费倾向（如图 3) 进行了分析，如上文所述原因，边际消费倾向分析从 2010 年开始。 
可以看出，公众的体育边际消费倾向自 2010 年开始逐年降低，但降低趋势有所缓和，2013 年之后公众的体育边际消费倾向, 开始上升。体育彩票和体育消费用品的边际消费倾向都比 较大，说明在体育消费支出中，还是较侧重 “看得见” 的实体消费，服务性的 “感知类” 消 费发展市场有待进一步开发; 但两者波动都比较大，2012 年之前，体育彩票的边际消费倾向 大于体育用品, 2013 年反超体育彩票, 说明公众没有形成固定的体育消费意识, 受外界因素 影响较大。体育健身休闲的边际消费倾向是最低的, 但最为稳定, 且在逐步提升, 是体育消 费市场中具有较大发展空间的部分。另外，体育消费的结构较为单一，要注意引导公众的消 费偏好，逐渐转变和更新公众对体育消费的固有观念和意识，让公众体育消费的 “需求层次” 不仅仅徘徊于生理、安全或社交层次上的需求，还应向更高需求层次发展。

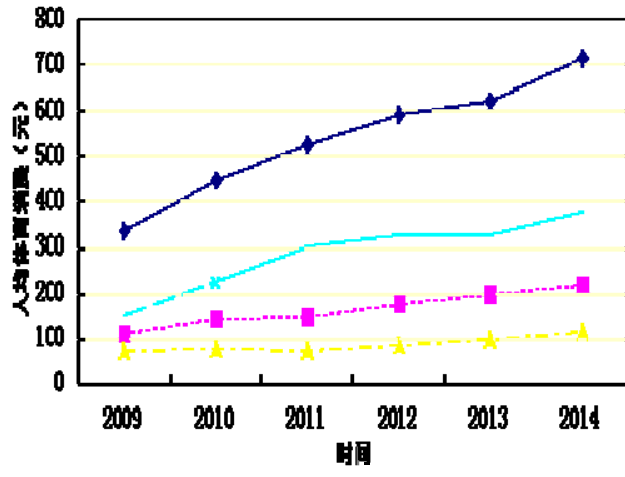

图2 2009-2014年体育消费及各类别变动

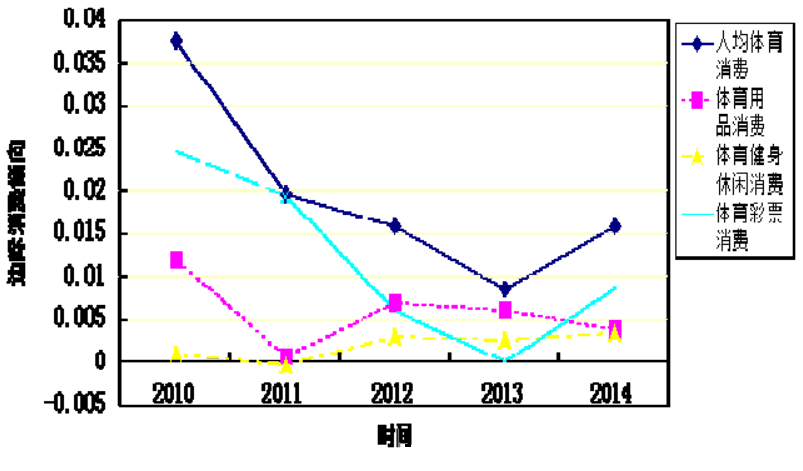

图3 2010-2014年体育消费及各类别边际消费

\section{3. 研究设计}

\section{1 样本选取及变量设置}

2015 年 8 月, 苏州市入列 “特大城市” [7], 经济发展水平位居全省前列, 市场化程度全 面提升, 作为市场发展的新兴动力, 苏州市体育产业门类健全多样, 具有稳定的经济环境和 人文环境，政府扶持引导政策健全，2014 年全市体育产业总规模 665.45 亿元，全市体育产业 增加值为 193.26 亿元，占苏州 GDP 的 1.4\%，远远超过国家占比水平， 2015 年 8 月，苏州被 列为全国体育产业联系点城市 ${ }^{[8]}$ 。因此, 本文选取苏州市作为研究样本对体育产业结构与体 育消费的关系进行实证研究。

体育产业结构指标数据资料来源于历年全部规模以上工业企业的全面调查资料、全部限 额以上批发零售企业的全面调查资料、规模以上服务业企业调查资料、行政事业单位调查资 料以及规模以下工业企业和限额以下批发零售企业的相关资料; 体育消费数据资料来源于城 乡居民住户抽样调查资料和部分体育活动单位调查资料。参照《文化及相关产业增加值核算 办法》，对 7 年的相关数据进行测算。为了更明确直观地体现数据发展的变动程度及变化情 况, 本研究对分析数据进行了环比处理, 得到动态相对数。

\section{2 变量设置}

\section{2 .1 自变量}

由于本文研究区间为 2008 年至 2014 年，根据《江苏省统计局、江苏省体育局关于转发 体育及相关产业分类（试行）的通知》（苏统[2008]84 号）要求，苏州市体育及相关产业指 标包括: 体育组织管理活动, 体育场馆管理活动, 体育健身休闲活动, 体育中介活动, 其他 体育活动, 体育用品、服装、鞋帽及相关体育产品的制造, 体育用品、服装、鞋帽及相关体 育产品的销售, 体育场馆建筑活动八个类别。因此, 我们通过这 8 个指标对体育产业结构进 行测量，相关指标设定见表 1：体育产业结构的内容分析测量指标统计表。 
表1＼cjkstart体育产业结构的内容分析测量指标统计

\begin{tabular}{|c|c|c|}
\hline 变量符号 & 变量名称 & 变量解释 \\
\hline SOM & 体育组织管理活动 & $\begin{array}{r}\text { 专门为社会公众提供比赛、训练、辅导和管理的组织的活动, 如群众性体育组织、 } \\
\text { 专项性体育管理组织的活动。 }\end{array}$ \\
\hline SVM & 体育场馆管理活动 & $\begin{array}{c}\text { 为社会公众提供观赏比赛和专业训练的体育场馆管理活动, 如综合性比赛场馆, 训 } \\
\text { 练用场地的管理活动。 }\end{array}$ \\
\hline SFL & 体育健身休闲活动 & 为社会公众提供的可供参与和选择的各种健身休闲活动场所的管理活动。 \\
\hline SIA & 体育中介活动 & 社会公众提供的体育中介活动, 如各种体育商务代理、经纪、咨询活动。 \\
\hline Отн & 其他体育活动 & 体育培训、体育传媒服务、体育市场管理等服务活动。 \\
\hline SPM & $\begin{array}{l}\text { 体育用品、服装、鞋帽 } \\
\text { 及相关体育产品的制造 }\end{array}$ & 提供体育服务所必须的体育用品、服装、鞋帽及相关体育产品的制造活动。 \\
\hline SPS & $\begin{array}{l}\text { 体育用品、服装、鞋帽 } \\
\text { 及相关体育产品的销售 }\end{array}$ & 提供体育服务所必须的体育用品、服装、鞋帽及相关体育产品的销售活动。 \\
\hline SGP & 体育场馆建筑活动 & 提供体育服务所必须的体育场馆建筑活动。 \\
\hline
\end{tabular}

\subsection{2 因变量}

体育消费（SC）。公众的体育消费水平为体育产业的发展注入活力，体育产业结构的不 同指标也会对体育消费水平的增长产生不同的影响, 如体育用品的制造和销售能刺激公众体 育消费 ${ }^{[9]}$, 但对体育用品的消费支出可能阻碍对其他产品的消费; 体育场馆的建筑和有效管 理能够吸引公众进行体育消费 ${ }^{[10]}$, 但层次的不同可能抑制理性顾客的消费冲动。体育产业结 构对体育消费的影响分析不能仅从主观角度出发, 需要进行客观的的统计分析, 本研究衡量 体育消费水平的指标为体育消费总额。

\subsection{3 控制变量}

体育产业结构对体育消费的影响还可能受其他因素的影响, 如经济增长、相关产业发展 等 ${ }^{[11]}$ 。为了提高分析精确度，本文将宏观环境下保障层面的的全市 GDP、第三产业（TIn） 和体育服务业（SSI）以及提供层面的涉及到体育及相关产业单位（Uni）和体育产业从业人 员 $(E m p)$ 作为控制变量。

\section{4. 研究结果}

\section{1 描述性统计}

表2 研究变量的描述性统计

\begin{tabular}{lccccc}
\hline Variable & Obs & Mean & Std. Dev. & Min & Max \\
\hline SC & 6 & .1238475 & .2148324 & -.250541 & .350016 \\
SOM & 6 & .3933561 & .0913345 & .2902577 & .5344077 \\
SVM & 6 & .0736102 & .1020686 & 0 & .2468733 \\
SFL & 6 & .1842741 & .1656145 & .0283511 & .4712382 \\
SIA & 6 & .182052 & .1855685 & -.0019339 & .4643017 \\
Oth & 6 & .2773762 & .2695652 & .0199755 & .689988 \\
SPM & 6 & .1654864 & .0991261 & .0427488 & .3006068 \\
SPS & 6 & .2018902 & .0731755 & .1287024 & .2991302 \\
SGP & 6 & .0587822 & .5753014 & .1 & .6148562 \\
GDP & 6 & .1181301 & .0507443 & .0572532 & .1923348 \\
TIN & 6 & .1644061 & .0525035 & .089374 & .252126 \\
SSI & 6 & .2147651 & .0663087 & .0221031 & .2874866 \\
Uni & 6 & .1349595 & .0620556 &. .0831169 & .2092366 \\
Emp & 6 & .0481019 & .0816723 & .1290323 \\
\hline
\end{tabular}

表 2 是对研究变量的描述性统计结果, 可以看出, SC (体育消费总额) 环比增长率均值 为 0.124 , 在 $-25.05 \%$ 与 $35.0 \%$ 之间变动, 标准差为 0.215 , 波动相对较大, 说明虽然体育消费 总额在 2009 年之后逐年上升, 但增长率不稳定, 以平均值为标准上下浮动。

在体育产业各项指标中, 体育组织管理活动 (SOM) 增加值平均增长率最高, 标准差较 小, 说明体育组织管理活动增加值历年来一直平稳提升, 环比增长率稳定性较好; 体育场馆 建筑活动 (SGP) 增加值增长率平均值最低, 离散度最高, 但增长率最大值是最高的, 说明 近几年提供体育服务所必须的体育场馆建筑活动较受重视, 发展速度有明显提升; 而体育场 馆管理活动 (SVM) 环比增长率均值较低, 标准差适中, 说明体育场馆管理活动和利用效果 一般。 


\section{2 实证分析}

为进一步分析体育产业结构的不同指标对体育消费的影响关系，本文在描述性统计的基 础上, 作了基于 Eviews 数量经济学软件和 Stata 统计分析软件的实证分析。

\subsubsection{IRF分析}

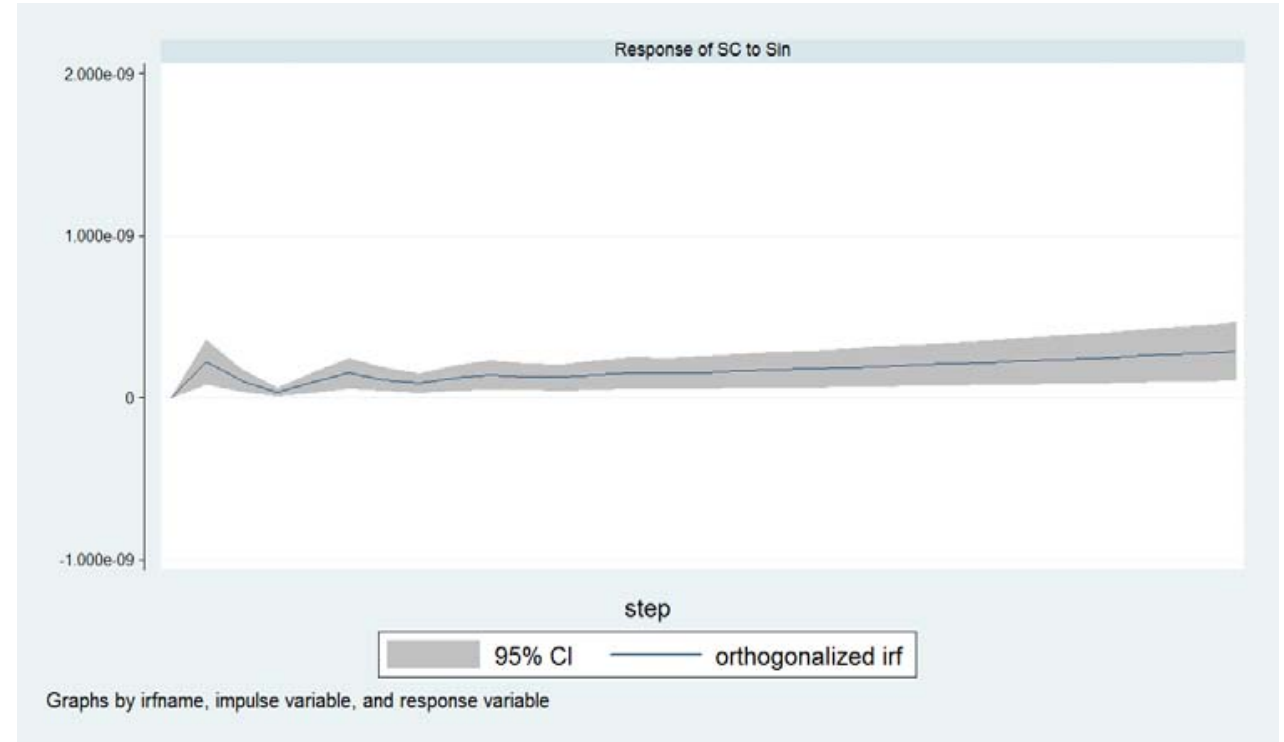

图 $4 \mathrm{SC}$ 对 $\mathrm{Sin}$ 的扰动的响应

通过脉冲函数可以衡量来自随机扰动项的一个标准差变动对变量现值及未来取值的影响

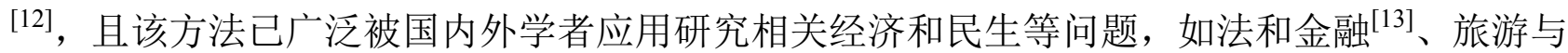

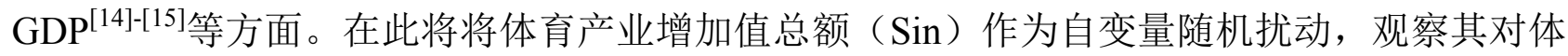
育消费 (SC) 的影响。首先对 SC 与 Sin 做 VAR 模型操作, 确定滞后阶数, 检验各阶系数联 合显著性、残差相关性、VAR 系统稳定性等符合条件之后，进而做脉冲函数分析，得到如图 3 所示的脉冲响应函数图, 横轴表示冲击作用滞后区间, 纵轴表示脉冲响应函数大小, 灰色 区域表示 $95 \%$ 的置信区间。

可以看到，体育消费对体育产业的扰动产生了响应，虽然相应值不高，但却呈现出长期 正向响应的趋势。前几期响应波动较大，在第一期没有做出立即的响应，反而是在第二期时 响应几乎达到最大, 如此反复之后体育产业对体育消费扰动的响应缓慢增加趋于稳定。这说 明体育产业对体育消费存在着冲击效应, 体育产业发展总供给或总需求在一定时期内变化明 显, 使得体育消费受到提高或降低的影响。这可能是由于, 在 2008 年北京奥运会之后, 体育 的产业价值更加凸显, 体育产品需求增加、体育赛事影响力空前提升, 随后又出台了一系列 促进体育产业发展的相关规划和政策，这都刺激了体育产业发展的公众需求和规模需求。然 而，体育产业结构始终在补充和完善之中，结构分类的合理性、科学性和适用性是其他工作 顺利开展的基础, 国家体育局经济司分别在 2008 年和 2015 年两次出台体育产业统计分类的 相关办法, 这也是一项不断探索、精益求精的课题。

4.2.2 Pearson相关性分析

表 3 研究变量的相关性检验

\begin{tabular}{|c|c|c|c|c|c|c|c|c|c|c|c|c|c|c|}
\hline & SC & SOM & SVM & SFL & SIA & Oth & SPM & SPS & SGP & GDP & TIN & SSI & Uni & Emp \\
\hline SC Pearson Correlation & 1 & & & & & & & & & & & & & \\
\hline $\begin{array}{l}\text { SOM Pearson } \\
\text { Correlation }\end{array}$ & $-.445^{*}$ & 1 & & & & & & & & & & & & \\
\hline $\begin{array}{l}\text { SVM Pearson } \\
\text { Correlation }\end{array}$ & .114 & -.102 & 1 & & & & & & & & & & & \\
\hline SFL Pearson Correlation & .153 & -.068 & $.756^{* *}$ & 1 & & & & & & & & & & \\
\hline SIA Pearson Correlation & .422 & -.160 & $.466^{*}$ & $.684^{* *}$ & 1 & & & & & & & & & \\
\hline Oth Pearson Correlation & $.433^{*}$ & -.104 & .470 & $.689 * *$ & $.778 * *$ & 1 & & & & & & & & \\
\hline $\begin{array}{l}\text { SPM Pearson } \\
\text { Correlation }\end{array}$ & $.615^{* *}$ & .326 & -.248 & -.154 & .278 & .323 & 1 & & & & & & & \\
\hline SPS Pearson Correlation & .173 & .042 & $-.636^{*}$ & -.403 & .269 & .249 & .131 & 1 & & & & & & \\
\hline
\end{tabular}




\begin{tabular}{|c|c|c|c|c|c|c|c|c|c|c|c|c|c|c|}
\hline $\begin{array}{l}\text { SGP Pearson } \\
\text { Correlation }\end{array}$ & $.555^{* *}$ & $\begin{array}{l}-.798^{*} \\
*\end{array}$ & $.460^{*}$ & $.476^{*}$ & 411 & 382 & -.281 & -.223 & 1 & & & & & \\
\hline GDP Pearson & $.644 * *$ & .312 & -.264 & -.185 & 125 & 178 & $.761 * *$ & .032 & -.075 & 1 & & & & \\
\hline Correlation & & & & & & & & & & & & & & \\
\hline TIN Pearson Correlation & $.698^{* *}$ & .244 & -.242 & -.217 & .027 & .078 & $.773 * *$ & -.114 & -.078 & $.775^{* *}$ & 1 & & & \\
\hline SSI Pearson Correlation & $.731 * *$ & $\begin{array}{l}-.575 * \\
*\end{array}$ & .231 & .336 & $.665 * *$ & $.660 * *$ & $.438^{*}$ & -.002 & $.719 * *$ & $.448^{*}$ & $.452^{*}$ & 1 & & \\
\hline Uni Pearson Correlation & -.136 & $.415^{*}$ & .049 & .180 & .137 & .172 & -.028 & .159 & .064 & .355 & 177 & -.072 & 1 & \\
\hline $\begin{array}{l}\text { Emp Pearson } \\
\text { Correlation }\end{array}$ & 390 & . 099 & $.710^{* *}$ & $.583^{* *}$ & 177 & .208 & .303 & $\begin{array}{l}-.714^{*} \\
*\end{array}$ & .096 & 180 & .037 & .252 & -.261 & 1 \\
\hline
\end{tabular}

由变量的 Pearson 相关系数检验结果可以看出, 体育消费 (SC) 与体育用品及相关体育 产品的制造（SPM）和体育场馆建筑活动（SGP）在 $1 \%$ 的水平上显著正相关, 与体育培训、 体育传媒服务等其他体育活动 $(\mathrm{OTH})$ 在 $5 \%$ 的水平上显著正相关, 而与体育组织管理活动 （SOM）确显示出在 $5 \%$ 的水平上显著负相关, 这说明体育产业结构中的体育用品、服装、 鞋帽及相关体育产品的制造、体育场馆建筑活动及体育传媒服务等其他体育活动的发展有利 于体育消费总额的提升, 体育组织管理活动却没有发挥出明显的促进作用。另外, 从各变量 间相关系数来看, 都没有超过共线临界值 0.8 , 因此变量间不存在自相关的共线性, 不会对结 果产生较大影响。进一步分析得知, 控制变量中 GDP、第三产业发展（TIN）及体育服务业

(SSI) 的发展与体育消费在 $1 \%$ 是水平上显著正相关, 能对体育消费起到促进和保障的作用。 而体育场馆管理活动（SVM）、体育健身休闲活动（SFL）、体育中介活动（SIA）、体育用 品、服装、鞋帽及相关体育产品的销售（SPS）以及体育产业从业人员（Emp）虽然相关系数 为正, 但并没有表现出显著的相关性, 说明这几大变量并没有发挥出对体育消费的促进作用。 4.2.3 多变量回归检验

表 4 多变量回归分析结果

\begin{tabular}{|c|c|c|c|c|}
\hline \multirow[b]{2}{*}{ Variables } & \multicolumn{4}{|c|}{ Dependent variable:SC } \\
\hline & $\begin{array}{c}1 \\
\beta \text { Coef }\end{array}$ & $\begin{array}{l}\text { Robust } \\
\text { Std.Err }\end{array}$ & $\begin{array}{c}2 \\
\beta \text { Coef }\end{array}$ & $\begin{array}{l}\text { Robust } \\
\text { Std.Err }\end{array}$ \\
\hline \multicolumn{5}{|l|}{ Control: } \\
\hline$G D P$ & $3.0168^{* *}$ & $(.3980)$ & $3.6206^{* *}$ & $(.5896)$ \\
\hline$T / N$ & $4.1490 * *$ & $(.4085)$ & $4.8218^{* *}$ & (1.4661) \\
\hline SSI & $2.7259 * * *$ & $(.0995)$ & $2.5297 * * *$ & $(.1121)$ \\
\hline Uni & -.4706 & $(.2236)$ & -1.2303 & (.7149) \\
\hline Emp & .6581 & $(1.011)$ & .8937 & (1.1215) \\
\hline \multicolumn{5}{|c|}{ Explanatory variable: } \\
\hline SOM & & & -1.0456 & $(.0535)$ \\
\hline$S V M$ & & & .24067 & $(.0455)$ \\
\hline$S F L$ & & & .1987 & $(.1409)$ \\
\hline$S / A$ & & & $.4890^{*}$ & $(.3247)$ \\
\hline Oth & & & $.3453^{*}$ & $(.2591)$ \\
\hline$S P M$ & & & $1.3317 * * *$ & $(.8549)$ \\
\hline SPS & & & -.5064 & $(1.4459)$ \\
\hline$S G P$ & & & $.2072 * *$ & $(.15534)$ \\
\hline cons & & & -.5236 & $(.13236)$ \\
\hline Number of obs & 6 & & 6 & \\
\hline R-squared & 0.8324 & & 0.7956 & \\
\hline Prob $>$ F & 0.0000 & & 0.0001 & \\
\hline
\end{tabular}

注: 括号前数字为相关系数(Coef.), 括号内数字为标准误(Std. Err); * 表明两个变量在 $10 \%$ 的水平上显著相关, ** 表明两个变量在 $5 \%$ 的水平上显 著相关, $* * *$ 表明两个变量在 $1 \%$ 的水平上显著相关。

由表 4 可以看出, 多变量回归检验结果具有较好的拟合优度, 进一步分析得出, 在控制 变量中, GDP、第三产业发展（TIN）及体育服务业（SSI）的 P 值分别小于 0.01 和 0.05 , 且 系数为正, 为显著正相关; 在因变量中, 体育用品及相关体育产品的制造（SPM）与体育场 馆建筑活动 (SGP) 与体育消费 (SC) 分别在 $1 \%$ 和 $5 \%$ 的水平上显著相关, 且系数为正, 为 显著正相关; 体育传媒服务等其他体育活动（OTH）与体育中介活动（SIA）与体育消费（ $\mathrm{SC}$ ) 
在 $10 \%$ 的水平上显著相关, 同样系数为正, 为显著正相关, 而体育组织管理活动（SOM）及 体育及相关产业单位（Uni）不仅没有表现出显著的相关性，而且系数为负，对体育消费都没 有发挥出应有的推动和督促作用。

\section{5. 结论及政策建议}

\section{1 结论}

（1）体育用品及相关体育产品的制造与体育消费为显著的正相关关系。公众参与体育活 动的方式和类别在不断丰富, 对体育用品及相关产品的需求也在不断增长, 其价格、质量及 品牌效应更是吸引消费者进行体育消费的主要竞争所在。而体育用品及相关体育产品的销售 对体育消费并没有起到明显的促进作用，说明体育市场产业链有待完善，在技术域提供了实 体产品之后，服务域不能高效率、高效益地引导公众进行体育消费。

（2）体育场馆建筑活动与体育消费为显著的正相关关系。公众的消费结构和需求层次在 不断变动, 室内外场地设施建设作为公众进行休闲健身和体育锻炼的基本设施保障, 是公众 追求自我提升、参与体育消费的重要场所。然而体育场馆管理活动并没有对体育消费起到明 显促进作用，说明体育场馆的管理运营机制和利用情况存在一定的欠缺。

（3）体育中介活动及体育传媒服务等其他体育活动与体育消费为显著的正相关关系。体 育中介活动是体育市场的一部分, 体育中介组织和从业人员的逐年增加、营销渠道的多样、 业务范围的拓宽和规模的扩张都刺激了公众进行体育消费欲望; 其他体育活动包括体育培训 服务、体育传媒服务、体育市场管理服务等内容, 在不同时期又被注入新的血液, 如互联网 体育、信息服务、旅游活动等内容, 这些内容是体育产业发展到一定阶段公众产生新的需求 的客观体现，丰富着体育产业的内涵，为体育消费创造了更加丰富的产品和服务。

（4）GDP 发展、第三产业发展及体育服务业发展与体育消费为显著的正相关关系。说明 体育消费的提升离不开地区经济的发展水平以及所属的产业环境。体育消费是一种较高层次 的消费行为 ${ }^{[16]}$, GDP 水平越高, 体育产品与服务的供给水平越高, 人们的消费偏好也往往趋 于更高层次的追求，这都提升了体育消费的活跃度。另外，国家对第三产业和体育服务业的 政策支持、多元市场体系的发展等都为体育消费提供了保障、注入了活力。

（5）体育组织管理活动及体育及相关产业单位与体育消费都表现出不显著的负相关性。 体育组织管理业是体育产业的核心产业, 包括公共体育事务、体育社会组织及其他体育的管 理, ${ }^{[17]}$ 体育及相关产业单位在体育市场经济中发挥直接的关联和运作功能, 但两者没有发挥 应有的推动力, 这可能是由于目前的管理体制还没有完全适应体育市场经济的发展以及消费 市场中缺乏有效的规范和监管所导致。

\section{2 政策建议}

（1）完善体育市场产业链，使体育用品及相关体育产品在制造、销售以及后期服务等方 面环环相扣, 不仅要注重形成体育用品及相关体育产品的技术优势和质量优势, 还要根据目 标市场选择销售模式及策略, 塑造产品的服务优势, 增加消费者附加价值, 建立消费者忠诚 度, 最终形成体育用品及相关体育产品的品牌竞争优势, 提升体育消费水平。

（2）合理规划体育场馆建筑活动，在相关政策规范下，协调好体育场馆现有改造和规划 新建的关系，使架构层面、投入模式、类型及配套等满足现实的需求，建设能够提供多元化、 多层次服务的体育场馆。建筑活动是资源的 “投入”，有效管理才是资源的 “盘活” ，对体 育场馆进行科学布局和科学管理, 通过改造、提升、包装、充实、丰富和拓展场馆资源, 实 现运营方式的转型升级和改革创新, 引入多方主体, 带动人气、刺激消费、拉动效益。

（3）不断丰富体育产业业态, 通过创新消费方式、拓宽宣传渠道挖掘和刺激公众体育需 求。如通过各种媒介向公众提供信息服务; 开展 “多业助体” 的体育服务活动, 如互联网+ 的运用、旅游业、会展业、培训业、影视业、电竞业等与体育的多方融合, 打造新的体育消 费模式，满足公众不同群体、不同阶层的多方需求。 
（4）综合各地区发展的产业优势和地区特色，体育产业的发展与体育消费的引导应当与 地区发展规划和愿景相结合，与经济发展、产业结构和战略规划相结合，站在不同角度审视 体育消费行为, 注意不同经济水平群体的消费需求和结构的差异，引导公众进行体育消费的 “偏好” 和 “惯性”。

（5）加强体育组织管理和自我管理能力, 政府体育组织在体育市场中发挥好监督管理和 有效引导的作用, 从而规范体育市场健康有序发展; 体育社会组织应发挥好积极参与、主动 承担的作用, 从而丰富体育事业内涵, 推动全民健身、体育产业等事业的进程。另外, 还应 提升体育及相关产业单位间的管理协调能力以及体育产业从业人员的专业素养, 加强组织化 建设、助力体育产业发展、规范体育市场，起到进行体育消费的风向标作用。

\section{致谢}

本文为江苏高校品牌专业建设一期项目资助（项目编号：PPZY2015B107）的阶段性成果之一。

\section{References}

[1] National Development and Reform Commission.Issue notice of 《On the courses of action of boosting consumption and driving the transformation and update》(NDRC NO.[2016]832) [EB/OL]. http://www.sdpc.gov.cn/zcfb/zcfbtz/201604/t20160426_799488.html.

[2] Department of Political Science and Law of the State Physical Culture Administration. Sports development in " 13th Five-Year Plan ". [EB/OL]. http://www.sport.gov.cn/n10503/c722960/ content.html.

[3] Li Jian-zhong, Wang Cong-xian. Study on Relationship between sports consumption and the sports industry, China Business, vol.17, pp. 207-209, 2009.

[4] Yu Zhen-feng, Wang Qingwei, Ren Yuan-chun. Research on the Relationship Between Mass Sports Consumption and Sports Industry, Journal of Chengdu Physical Education Institute, vol.24, pp. 6-10, 1998.

[5] Zhu Han-yi. Practical Selection of Sport Industry Structure from the Sport Consumption in China, China Sport Science And Technology,vol.42, pp. 14-20, 2006.

[6] Li Guo-mao. Dynamic Mechanism Analysis of sports consumption growth pole theory, Commercial Times, vol.18, pp. 26-27, 2014.

[7] JiangSu Provincial Government. 《JiangSu Provincel urban system planning(2015-2030)》 [EB/OL]. http://www.jiangsu.gov.cn/ttxw/201508/t20150811_397672.html.

[8] Jiangsu Provincial Development and Reform Commission for Social Development. Suzhou was listed as the contact point city of sports industry [EB/OL].http://www.jsdpc.gov.cn/gongkai/ wjg/shfzc/shsy_8649/201508/t20150804_409402.html.

[9] Ren Bo. The study of the promotion of National fitness to sports consumption,Sports Culture Guide, vol.11, pp. 95-98, 2015.

[10]Cui Hai-yan. Sports Consume Situation and Expectation of the Citizen in Our Country, Sports Consume Situation and Expectation of the Citizen in Our Country, vol.24, pp. 32-36, 2007.

[11]Wang Wen-feng, Guo Wen-ting. Sports Consumption and Sports Industrialization and Economic Growth, Productivity Research, vol.1, pp. 144-147, 2005.

[12]Guo Wei. The Effects of Investment on Economic Growth and Its Path:The Analysis of Impulse Response Function, FINANCE AND TRADE RESEARCH, vol.5, pp. 1-7, 2005.

[13]Franklin A . Law, Finace and Economic Growth in China [Z] .Working Paper, 2002.

[14]Xiang Yan-ping, Jiang Cai-fang. The analysis of the Impulse Response about the Relationships between FTI, FDI and GDP, Journal of Applied Statistics and Management, vol.32, pp. 896-902, 2013.

[15]Hyun Jeong kim, Ming-Hsiang Chen, Soo Cheong "Shawn" Jang. Tourism expansion and 
economic development: The case of Taiwan, Tourism management, vol.27, pp. 925-933, 2006.

[16]Guo Bang-shi. Analysis of social factors affecting mass sports consumption, Market modernization, vol.29, pp. 144-146, 2008.

[17]Zhang Rui-lin. Study of sport industrial structure optimization in China, Journal of Physical Education, vol.18, pp. 21-26,2011. 